\title{
Neoaortic support hose
}

\author{
David P. Bichell, MD
}

\author{
From the Division of Pediatric Cardiac Surgery, Children's Hospital, Vanderbilt University, Nashville, Tenn. \\ Disclosures: Author has nothing to disclose with regard to commercial support. \\ Received for publication Sept 29, 2015; accepted for publication Oct 1, 2015; available ahead of print Nov 3, \\ 2015. \\ Address for reprints: David P. Bichell, MD, William S. Stoney, Jr, Chair in Surgery, Chief, Pediatric Cardiac \\ Surgery, Monroe Carell, Jr, Children's Hospital, Vanderbilt University, 5241 Doctor's Office Tower, \\ 2200 Children's Way, Nashville, TN 37232-9292 (E-mail: david.bichell@vanderbilt.edu). \\ J Thorac Cardiovasc Surg 2016;151:165-6 \\ $0022-5223 / \$ 36.00$ \\ Copyright (C) 2016 by The American Association for Thoracic Surgery \\ http://dx.doi.org/10.1016/j.jtcvs.2015.10.006
}

Dramatic neoaortic root dilation is well described after the Ross procedure, with $z$ scores greater than 8 commonly seen. ${ }^{1}$ Reintervention to repair neoaortic root aneurysm for risk of rupture after the Ross procedure is uncommon and is seldom indicated, but reintervention for progressive neoaortic valve insufficiency is not uncommon and has been a reason for some institutions to lose enthusiasm for the Ross operation.

An external stabilization of the autograft has neutralized some of the risk of autograft dilation and has restored some enthusiasm for the Ross procedure as an excellent and durable alternative to mechanical or biologic prostheses. ${ }^{2}$ The impressive success of catheter-based pulmonary valve replacement has reversed a second source of concern for the Ross operation by reducing the need for repeated surgeries to replace the pulmonary valve. External autograft support at the time of the Ross operation, the expanding use of catheter-based pulmonary valve replacements, and ongoing favorable long-term Ross outcomes support an expanding use of the Ross operation in adult and pediatric patients today.

Maintaining the competence of the neoaortic valve is critical to the long-term success of the Ross procedure, and neoaortic root geometry is a major determinant of neoaortic valve competence. Although an external stabilization of the autograft has significantly improved the incidence of root distortion in adults, it is currently not a possibility in the infant or growing child.

The work of Francesco and colleagues ${ }^{3}$ in this issue of the Journal describes a concept that could be part of the next quantum improvement in Ross neoaortic longevity and may hold some answers to the challenge of accommodating somatic growth. Resorbable early reinforcement of the autograft an initial circumference, with a construct that is laced with polytetrafluoroethylene that unfurls to a larger circumference with time, may allow support that melts away stepwise with growth and a root that dilates to mimic growth.

Spatial data acquired from magnetic resonance imaging, 3-dimensional modeling, and rapid prototype construction by 3 -dimensional printing are now commonplace, with

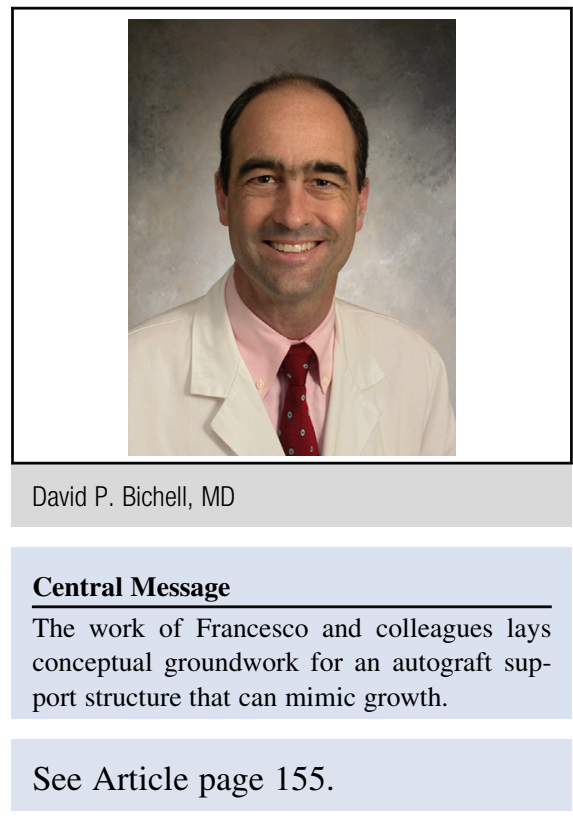

lots of medical applications already emerging. Among them, finite-element models have been used to make patient-tailored external aortic root mesh support for patients with Marfan syndrome, with encouraging decade-long follow-up. ${ }^{4}$ This method permits a rapidly produced, anatomically personalized external mesh prosthesis that can preserve the exact sinus of Valsalva geometry of a particular aorta or autograft aorta.

Combining a rapid and specific manufacture with a stepwise circumference-enlarging sheath may set the stage for the next refinement in root support that can navigate the timeline of somatic growth. It is appealing to envision an anatomically tailored autograft support construct with nested layers of resorbable material, an ultimate polytetrafluoroethylene support layer that unfurls to a predetermined and anatomically optimal shape and caliber. Successive layers dissolve on a programmed time line, releasing the vessel to expand and allowing dilation that mimics growth. Tomorrow's Ross operation may have a tailored support hose, preserving the sinuses of Valsalva, with programmed, proportioned growth potential that is determined by the specialized material properties of its layers. The work of Francesco and colleagues ${ }^{3}$ lays inspired groundwork for an emerging story of a "virtuous cooperation between biologic and synthetic materials."

\section{References}

1. Pasquali SK, Cohen MS, Shera D, Wernovsky G, Spray TL, Marino BS. The Relationship between neo-aortic root dilation, insufficiency, and reintervention 
following the ross procedure in infants, children, and young adults. J Am Coll Cardiol. 2007;49:1806-12.

2. Ungerleider RM, Ootaki Y, Shen I, Welke KF. Modified Ross Procedure to Prevent Autograft Dilatation. Ann Thorac Surg. 2010;90:1035-7; discussion 1037.

3. Nappi F, Spadaccio C, Fraldi M, Montagnani S, Fouret P, Chachaues JC, et al. A composite semiresorbable armored scaffold stabilizes pulmonary autograft after
Ross operation. Mr Ross's dream fulfilled. J Thorac Cardiovasc Surg. 2016; 151:155-64.e1.

4. Treasure T, Takkenberg JJ, Golesworthy T, Rega F, Petrou M, Rosendahl U, et al. Personalised external aortic root support (PEARS) in Marfan syndrome: analysis of 1-9 year outcomes by intention-to-treat in a cohort of the first 30 consecutive patients to receive a novel tissue and valve-conserving procedure, compared with the published results of aortic root replacement. Heart. 2014;100:1-7. 